\title{
The Virtues of Reason and the Problem of Other Minds: Reflections on Argumentation in a New Century
}

\section{G. ThOMAS GOODNIGHT}

\author{
Annenberg School of Communication \\ University of Southern California \\ Los Angeles, California 91775 \\ U.S.A. \\ gtg@usc.edu
}

\begin{abstract}
From early modernity, philosophers have engaged in skeptical discussions concerning knowledge of the existence, state, and standing of other minds. The analogical move from self to other unfolds as controversy. This paper reposes the problem as an argumentation predicament and examines analogy as an opening to the study of rhetorical cognition. Rhetorical cognition is identified as a productive process coming to terms with an other through testing sustainable risk. The paper explains how selfsustaining risk is theorized by Aristotle's virtue ethics in the polis. Moral hazard is identified as a threat to modern argument communities.
\end{abstract}

Résumé: Depuis le début de la modernité, les philosophes se sont engagés dans des discussions sceptiques concernant la connaissance de l'existence des esprits et de leur état. Leurs raisonnements analogiques qui partent du soi à l'autre se déroulent en controverse. Dans cet article on repose le problème comme une situation difficile d'argumentation et on examine l'analogie comme une ouverture à l'étude de la cognition rhétorique. On identifie la cognition rhétorique comme un processus productif qui arrive à accepter l'existence d'un autre esprit en mettant à l'épreuve le risque durable. On explique comment l'auto-maintenance du risque est théorisée par l'éthique de la vertu d'Aristote dans la polis. L'aléa moral est identifié comme une menace pour les communautés d'arguments modernes.

Keywords: Argument culture, other minds, rhetorical cognition, institutional logic, moral hazard, community of practice, risk, reasonableness, contingency.

\section{Introduction}

OSSA is a delightful conference. I have attended over the years and participated in a broad range of discussions. Argumentation itself appears continuously under convivial review. We roundly agree that reasons are important. On other items, consensus eludes. Differences persists over argumentation as an ontologi- 
cal feature of the human condition, an anchor for epistemic systems, an expression of practical knowledge, an outcome of linguistically constituted rules and speech acts, and relational grounds for initiating and maintaining critical communication. The range of discussion crosses disciplines, generates new enthusiasms, motivates connections, and engages us in major projects of informal logic, critical thinking, pragma-dialectics, commitment, advocacy, controversy, cognition, AI and more. Our critical-cosmopolitan, global project flourishes. I appreciate the energy, foresight, and thinking of my colleagues, especially as I always discover new things afoot.

The temptation arises to pose the question: how may argumentation study address the global circumstances of the $21^{\text {st }}$ century? This question touches my own line of work: critical argumentation studies. Such inquiry visits controversies of the past to extrapolate similarities and interpolate differences into present. Giambattista Vico's Rhetoric is my favorite collection of notes because it situates argument as advocacy in civil society, setting the grounds for the New Science which discovers change in the expressions of mind that yield an age. In the long $18^{\text {th }}$ century, Vico provided an alternative to Descartes's mindbody dualism, situating mind in practical training, the colors of rhetoric, and the ingenuity of address deployed to negotiate the circumstances of a time (Hampshire, 1969, pp. 475-495). In the $21^{\text {st }}$ century, globalization challenges us, similarly, to extend standing models in concrete ways. At its core, I agree that argumentation addresses the basic predicament of "having to combine effectiveness and reasonableness" (Houtlosser and van Eemeren, 1997; van Emeren, 2010, p. 40). In the contemporary world, predicaments expand and multiply across contexts. Argumentation works to address multicultural engagements, network connections, (post)modern institutions, and new media (Goodnight 2003). The very rules presupposed in everyday practices have turned reflexive. Thus, in affirming, developing or veering from new contexts, communities of argument undergo a range of corrections, repairs, and innovations - as the rules of reason are turned back upon themselves by self-authorized questioning. In this address, I do not offer a new model of argument; but, I do want to extend an invitation for lateral thinking across contemporary contexts. In this respect, I work through varied topics but return to a central question: How can the problem of other minds be posed anew to engage the virtues of argument in a time of global change?

The problem of other minds is a philosophical debate that I address with some hesitation. Paul Noordhof informs us that 
"the issues which lie at the heart of discussions of philosophy of mind have not changed and are unlikely to change in the near future, or even, I hazard a guess, the quite distant future" 2011, p. 239). The controversy defines a robust line of practice laid down within the modern field of philosophy. Its stakes could not be higher. Should we not be able to establish the existence of other minds or secure knowledge of their content, we risk...solipsism. Boxed into a corner by un-perspicuous reasoning, the alienating conclusion follows: "I am the only mind which exists" or "The mental states of others are unknowable to me - or anyone else." Theodore Everett $(2000,213)$ tantalizes us with the flatly ugly outcome: "As far as each us can tell subjectively, after all, he might be a proverbial brain in a vat, being fed his subjective experiences through a set of wires." A demon may be dreaming this whole operation. Yet, despite this stated anxiety, philosophers confidently engage in technical exchanges that parse whether, how and to what extent we can claim to know the other as our self. These elaborate exchanges are not infrequently accompanied by this reassurance: We know there are other minds. We behave as if we do all the time. Yet, we may overstate the grounds for our certainty. The asymmetry of access - to one's own thoughts as privileged versus those of others, that may or may not be different-cautions skeptical reserve. Address of this "ego-predicament" has touched philosophical controversies over mind, brain, consciousness, awareness, perception, behavior and alteriority itself.

I wish to strategically resituate the initial formulation of the problem: particularly in relation to its often proposed solution, the argument from analogy. In brief, I see the argument from analogy - to equate knowledge of self as like that of other-as the camel's nose under the tent, opening the way to other minds through acts of rhetorical cognition. Aristotle's virtue argument builds a model where indirect, collaborative thinking flourishes in excellence. I conclude that virtue argument is limited by aspects of our contemporary post-polis pluralistic culture, even though — oddly enough — moral hazard appears to be nearly universal.

\section{The problem of other minds and analogy}

The problem of other minds goes back to Descartes mind-body dualism. It was put in its modern version by Thomas Reid. Skepticism notwithstanding, he argues, "common sense" secures our sense of others. Common sense insists that: "(i) Everything 
of which I am conscious exists. (ii) The thoughts of which I am conscious are the thoughts of a being I call 'myself', my 'mind' or my 'person'. (iii) Those things that I distinctly remember did really occur. (iv) Those things that I distinctly perceive by my sense do really exist and are as I perceive them to be. (v) There is life and intelligence in our fellow[s] ... with whom we converse." (vi) "Certain features of the countenance, sounds of the voice and gestures of the body, indicate certain thoughts and dispositions of mind." (vii) Finally, "there is a certain regard due to human testimony in matters of fact" (Avramides, 2001, p. 88). Common sense promises security in understanding one's own mind and furnishes tools to read others; just not consistently nor all the time.

John Stuart Mill did not take common sense for granted. He posed the basic question: "By what evidence do I know, or by what considerations am I led to believe, that there exist other sentient creatures; that the walking and speaking figures which I see and hear, have sensations and thoughts, or in other words, possess Minds?" Mill secures his knowledge in the fact that others have "bodies like me" and "exhibit the acts, and other outward signs, which in my own case I know by experience to be caused by feelings." He deduces that there must be a mediating feature between feelings induced in response to an environment and behaviors that express reception. He knows that his mind mediates for him. Thus, "I bring other human beings, as phenomena, under the same generalizations which I know by experience to be the true theory of my own existence" (1872, pp. 243-244).

The result of this argument for the existence and knowledge of others constitutes an offer to resolve an epistemological problem concerned with justifying "beliefs about mental states other than our own" and a conceptual issue: "how is it possible to form a concept of mental states other than our own?" (Hyslop, 2010). The problems persist because of the acceptance of a fundamental asymmetry between knowledge of one's own mind and that of others. Whereas justification to know one's own thinking can be verified by more or less direct evidence that is internal and so privileged, claims to know the thinking of the others do not have similar access and therefore (assuming accurate knowledge of one's own mind) is in principle less trustworthy, if it is given any credence at all. Sayward defends Mill's problem as genuine: "While it is obvious to us that other people feel pain, we do not see how we know this"; hence, "skepticism is the affirmation that the problem of other minds is a real problem and the denial that there is any solution" (2003, p. 317).

(C) G. Thomas Goodnight. Informal Logic, Vol. 33, No. 4 (2013), pp. 510530. 
The analogical argument extending one's own thinking to others is weak because it cannot be checked. The inference drawn is indirect. Further, the analogy is "based on a single instance. Philosophers argue that the conclusion cannot be checked directly" (Hyslop, 2010). When the analogy is treated as conducive to tests of inductive reasoning, comparing a case of one against another does not martial sufficient proof. A.J. Ayer (1946) supports analogy by pointing out that judgment of others can be established by multiplicative corroboration. The inference appears more robust, but interlacing signs of behavior to judge a state does not ground the act of comparison itself.

Analogy and its sibling rivals contest across the journals. Norman Malcolm holds that an analogy would not be necessary should Mill have a criterion to distinguish other minds, but this begs the question. Thomas Olshewsky concedes there is no justification but that analogy follows a path of discovery, which argumentation per se does not; but this stipulates an arbitrary function for argument, rather than determining its validity conditions by relations to audiences. A. Hyslop and F.C. Jackson defend analogical argument as not requiring independent confirmation, just as the present is like the past, so is my mind like yours. Neither statement is verifiable strictly, but both are regarded as structured inferences, a matter of confirmation not verification (Fiegel, 1958, p. 985). Finally, Stemmer asserts that the problem can be resolved by judging the actions of others in reference to my own is the best criterion, thereby avoiding analogy altogether - but begging the question by shifting to a covert simile (1987, p. 109). Most recently, the whole issue has moved into the realm of technical analysis that moves from explication of the basic premises, extension, conclusion and counterclaims. Don Locke concludes that the argument from analogy is now dismissed "with an airy wave of the hand" (Locke, 1973, p. 153). Nevertheless, the debate persists and the issue remains open.

I propose to shift the problem of other minds. As it has unfolded, the problem invites doubt over whether a concept and knowledge of the other can be confirmed through checking. The discussion follows a problem-solution schema. What if the problem was a predicament? A predicament challenges an arguer to invent grounds for valid judgment in the face of uncertainty, made less easily resolved by competing communicative validity claims. Scientific, moral, ethical, personal, and discursive validity claims depend upon the ability of communicative reason to withstand appropriate objection (Habermas, 1983). Neuroscience tells us these days that we anticipate and respond to others

(C) G. Thomas Goodnight. Informal Logic, Vol. 33, No. 4 (2013), pp. 510530 . 
before our conscious minds know what we or they intend. Mimicry is geared by our brain as perception connects through mirror neurons with motor apparatus of the body. One sizes up the other before reasons are fully formed, even though subsequently one typically edits responses to selectively engage, tentatively explore and check the standing of one's own reaction (Franks 2010). Communication in everyday practices routinizes, integrates, and habituates engagement with others. Habits vary, but urban environments reward efficient communication. Common sense is shaped by confident alertness to the needs of self as expressed in relation to others while circulating through the day. The flow is disrupted when the projected grounds of valid address that underwrite communication in context are not granted (by oneself and/or an other), then brought into question by the turn to argue. What constitutes the make-up of such threshold moments?

\section{The turn to argue}

The turn to argue (to become argumentative) disrupts efficient exchange of activities. Arguing backs us up, exposes risks, and creates uncertainties - rendering evident something of the otherness of other minds. We don't agree, or unexpectedly discover that we do. As a preventing measure, common sense discounts the need to argue by the attribution of reasonable difference. If agreement cannot be reached, there are many possible causes one might attribute to the other: ignorance, stubbornness, bad faith, or blind indifference. These rationalizations notwithstanding, it is possible to admit that failure to agree may be justified. In the worlds of personal preference, professional practice, or public life, each of us has an idea of "reasonable" difference. There is always more that "one way to skin a cat" the saying goes. Different people choose different means, weight ends peculiar to their own experiences, and hold some actions within bounds and others not. Thus, one may support a claim as sound, even true, but recognize reasonable differences in its acceptability. This county values motorcycle helmets; that one does not. We do not carry handguns; they are packing. You say "potayto", I say "potahto." One's own common sense can be secured when disagreement is noticed-even when that which is common appears only to be reasonable difference. Reasonable differences cannot be sustained - when disagreement can no longer be overlooked, or when there are benefits for aligning thinking that otherwise differs. 
Other minds sometimes rupture the efficient transmission of communication and the means of discounting differences. Communication does rationalize routine with efficient, pragmatic re-enforcement. Rules of engagement are lodged in the customs of families, the habits of manners, the codes of the profession, the genre of composition, the schemas of practice or the traditions of public forums. Communication is reasonable because reciprocal expectations of what it means to assert and to differ are routinely met. These are confirmed by a more or less stable range of social and professional practices, certified by contract, and enforced by rule of law. The quality of an other mind comes in play when a predicament emerges: communication is urgent, differences can no longer be discounted, repairs become entangled in the rupture, but claims (and the means of resolving them) remain urgent and contested. Sometimes the variation is subtle: a shift of topic, a failure to make an objection, or an unexpectedly strong backing of a weak claimanything amiss may alert us as to a fundamental gap between one's own thinking and that of an other. When the difference can no longer be overlooked, the problem of other minds reveals itself as predicament.

Argument models often take the-turn-to-argue as a given. In conversation or dialogue, argument begins at the point of a claim made that encounters doubt. Aristotle holds that the architecture of an argument must be made with sound plans, good materials, competent work, and a good purpose. Under pain of relevance, contention is recognized only as an architectonic test of a well-built claim. Yet, engagement in disagreement itself is not so limited, each turn to argue carries with it risks and possibilities in the address of other minds. The turn to argue ranges from vociferous opposition to quiet demurral. The turn disrupts the informal flow of one's own thinking or punctures the flow of communication between us. The turn may be spontaneous or result from a decision well-strategized.

The social turn to argument has risks that a private thought may not. Communication becomes messy. Doubts may rise that are not expressible, articulation of reasons may take their own time, reasons apparently secure may lose standing or status. Even stable structures of reason are susceptible to the turn. Social norms both encourage and discourage disagreement; decisions carry forward with authority but remain open to scrutiny; the costs of disagreement earns one a reputation for being quarrelsome, but with self-imposed silencing one becomes a yes man. The turn to argue situates self and other in a social situa- 
tion where the virtues of reason are uncertain in relation to the consequences of action.

Giambattista Vico, the great opponent of Descartes, introduced his generation of students to the turn to argue. In contrast to skeptical undoing of social knowledge and a resulting mindbody dualism, Vico prefers to ground thought in the language of a time. Reason is a situated capacity to respond to others at an occasion. Human thinking is ensconced within forms of discourse and unfolds in mindful patterns (1996). Vico's grounded position of argument reminds us that the access to reasons and risks taken in address are not identical for every party in a dispute: defendant, prosecutor, defense, judge onlookers. The dignity of the participants stressed by the gravity of the subject influence the cognitive structures of argumentation. The institutional positioning of reasons in relation to the community is important, substituting rule of law for blood feuds and vengeance. Violence caps reason still in many parts of the world. The turn to argue itself cannot be taken for granted.

Even in a peaceful, commercial, pluralistic, democratic society, the turn to argue is not without risks. The risks associated with the turn comprise how we come to develop and revise standards for social customs as well as state of the art practices for modern fields. Such knowledge provides a route to engage and assess other minds. Three areas illustrate alternative risks.

3.1 Personal argument. In a personal relationship, contestation over a claim may be read as a sign of disrespect over judgment; yet, to avoid argument altogether, to forestall open disagreement, may result in baroque maneuvers to avoid topics, discussions, and direct address. Relationships grow cold. Bertrand Russell positions skepticism, claiming that a philosopher might pretend to know only a priori abstracts of time and space but once he gets cross with his spouse "you will see that he does not regard" the other "as a mere spatio-temporal edifice of which he knows the logical properties but not a glimmer of the intrinsic character." "We are therefore justified in inferring that his skepticism is professional rather than sincere," he concludes (1970, p. 3). Russell reminds us obliquely that common sense regard is shaped by gender conventions, as is perhaps the problem of other minds itself. Generally, from the point of view of identity, the basic predicament of argumentation becomes doing justice to both relevance and salience. There are risks to bracketing identity as only marginally relevant while addressing the situated salience of a claim, as well as the reverse. 
3.2 Institutional logic. In an institutional role, the turn to argue is fraught with risks to status, face, and reputation. On the one side, questioning, challenging, reviewing past mistakes or anticipating future hazards, may be distill an impression of a quarrelsome chap who is more interested in getting things right than in getting them done. From the standpoint of a decision-maker, the offer of input from diverse views may strengthen debate among subordinates, which heightens dissension in carrying out a decision, thereby perpetuating partisan rivalry. On the other hand, demanding consensus may result in "group-think" that makes a decision-maker vulnerable to well-cooked conclusions from cherry-picked evidence. Practice has risks whether the argumentative turn be encouraged as dialogue, debate or discussion.

3.3 Social standing and change. The question of who can argue, under what circumstances, with what limits to time and resources has synchronic and diachronic possibilities for study. A society is known for its exceptions to those who are deemed beyond self-representation, in need for further development, or have limited to access to varied forums. So, too, the turn to argument persists over times as reason is attributed as standing for certain groups and denied as savagery for others, rulers and ruled. The turn to argue offers a window into the configuration of power relationships, where the force of the better argument differentiates out groups over time as well as results in emancipatory, opposing argument to bring into questions exceptions to enabling some, while constraining others.

The problem of other minds re-conceptualized speaks to a predicament between common sense and the turn to argue. Analogy offers one such turn, a meeting point between minds where expectations can be reasonably projected and differences reasonably repaired through reflexive exchange. Note importantly, though, that analogy is only one among a number of possible tropes, each of which figures meeting points between minds in varied ways. Other figures could be used to the same end, putting into play language-games in which the other is invited to play along. Rhetorical cognition is the indirect knowledge gained about US as we put some issues into play, not others; figure authority or flatten it; build up or release emotion. The power of tropes to yield knowledge of other minds comes in how the conversation turns out to focus, extend, or cut short the common play of inquiry. 


\section{Rhetorical cognition and the virtues of reason}

The problem of other minds offers a predicament for communication; the question of other minds remain problematic not because evidence cannot be attained from penetrating the physical interiority of the brain; rather, the problem persists due to the asymmetry between claims to determine one's own mind and the imperfect projections in reading and responding, correcting and build upon the reasons of others. Although it is likely that one doesn't know one's mind as completely as one thinks (given that most of our brain activities are below conscious levels), it is certainly the case that in modern societies the other has a right of first refusal to claims of existence and standing. In that respect, communication is not reducible to an exchange of information that can be converted to taken-for-granted interactions; rather, communication depends upon an asymmetry where the assertion of meanings about (1) the ontological standing of the other or (2) the state of mind outside one's own may always, in principle, can be countered with refusal. If mirror neurons do indeed trigger basic awareness of the other, then the motor apparatus of our brains responds to perception; however, despite direct stimuli of anticipatory action, claims to "know" the other can only be secured through indirect testing, that is, symbolic or linguistic exchange. In this respect, resolution of the problem of other minds remains understandably a goad to philosophical speculation; but reformulated, the predicament does not so much frustrate as invite reflection on the turns to argue.

The argumentative turn has political and ethical risks that impact the development of one's character, the classics remind us. Preferences breed reputation. An assertive style utters direct claims, pronounces forceful truths, asserts aggressive judgments, and repels criticism vigorously. Those given to a thoughtful style employ indirection, suggestion, skeptical undoing, and balance dissoi-logoi into ataraxic withdrawal. Personal character grounds the habits developed as one grows into practices of communication, Aristotle found. Vico believes that the great orator is so rare because personal qualities are differentially distributed and to work on, say, memory, is to give up on another, like ingenuity (1996, p. 19). The community benefits from thoughtful arguers whose quality of mind in relation to action makes public the most timely, forceful arguments inviting judgment on behalf of the common good. Considered arguments generate thoughtful publics, good publics invite good argument.

Aristotle understood this unfinished space as he explained the human bipedal occupation of its unique ecological niche, the

(C) G. Thomas Goodnight. Informal Logic, Vol. 33, No. 4 (2013), pp. 510530 . 
polis. The enthymeme offers a participatory form where an arguer invites an audience to fill in evidence or a conclusion. Such collaborative cognitive work creates a consensus by arguing one's own ideas in a way so as to extend inferences of others, with the aim of rendering an informed decision regarding action. The work is critical, too, because a claim to act is always at best probable and succeeds only when it describes conduct in ways that avoid temptations to excess or to deficiency. Just as one grows in capacities for personal judgment through good habits of thinking, so too a public flourishes when its citizens are invited to test the cogency of topics. Argument entwines authority, emotion and reason into association for considered judgment. Aristotle's own system is often regarded as telic. Hence, argument is reduced to an instrument or tool of persuasion. What is overlooked in this simplification is that it's the dependence of rhetoric on inference, indirection that releases energy and feeds the dynamics of productive thinking taking topics through invention, reasons, and circumstance.

The present return of the popularity of virtue argumentation is found in the promise of the cognitive development of agency, the success of communities of practices, the flourishing of institutions hinges upon participatory enactment of argument in a mindful way that consistently anticipates, reviews, poses and resolves problems in the particular case; and, conversely from the imperfect resolution of cases the strengths and weaknesses of practice can be better understood. The virtues of argument appreciate the qualities of mind that are cultivated by engaged critical thinking. These qualities form habits for the individual. What is sometimes forgotten in understanding ethics and the development of agency is Aristole's link to rhetoric as a practice. The habits of rhetorical cognition bring to bear questions of common judgment that put at risk the community.

Aristotle's idea of rhetoric offers a strong model of argument in shaping a flourishing cognitive capacity for a community of argument. Virtue ethics extended to argumentation offers a promising way to cultivate good practices. It has limits though, which make our own work with argumentation challenging. The difference between self and other is compounded with asymmetries of standing, introduced in different periods, but still with influence.

4.1 Tradition and Advocacy. Aristotle's polis treasured the virtue of argument as arête, excellence. Argumentation is not always seated in a virtue culture. Questions of Republic and Empire weigh the rules of reason by the duties of representation and

(C) G. Thomas Goodnight. Informal Logic, Vol. 33, No. 4 (2013), pp. 510530. 
the challenges of advocacy. The choice to participate or withdraw is weighted against with whom one argues and agrees as much as what is true or false, right or wrong.

4.2 Modernity and Expertise. Specialized communities of practice now are organized by fields, which operate with quasiautonomous allegiance to the pursuit of intellectual questions. Expertise engages in the sophisticated testing and adaptation of technology to coordinate reasoning for individual cases on a broadly co-oriented scale. Scientific argument remains fundamentally a creature of basic research but the social production of "institutional argumentation" (van Eemeren and Houtlosser, 2003) places "other minds" into role accountability and performance. Role based argument must construct its own others, as client. The shared habits of experts create a taken-for-granted understanding of split address in and out groups. Exchange of reasons between client and expert add yet another level of asymmetry to argument.

4.3 Postmodernity and Identity. Aristotle's polis was the product of a slave culture that did not anticipate change. Strangers to the culture were barbarian whose contact was less frequent and threatening. We live in multi-cultural societies and exchange is carried by trade, circulation of populations, and publics. The state and the nation pull in sometimes compatible and sometimes different ways for the participation of citizens. Some workers are citizens, others are not. The identity of the other cannot be unified as inside or outside the community

\section{Argument and moral hazard}

What happens when the polis goes bad? Certainly, Aristotle had issues with tyrants in his own day. We need ask anew: How does argument fall into a weak or compromised state of practice? David Zarefsky (2011) reminds us that an argument culture rests on a community of practice; that such a community creates boundaries that define its interests, topics and activity types for securing judgment among relevant audiences. A community of practice flourishes when argument results in justified decisions that minimize error and maximize the chance of learning from mistakes. Just as Aristotle held that virtue ethics were necessary for an individual to reach an equilibrium in avoiding deficiency and excess, so we may examine a self-sustaining practice that itself occupies a niche of practice successfully, and standardizes 
criteria for the state of the decisions in questions of choice. Just as the individual thrives by discipline, so too, a community of practice thrives only when it avoids either acting precipitously on too little evidence or avoiding change in the face of evident necessity. When do communities of practice flourish? How do they weaken and ultimately fail?

It must be admitted that sometimes strategic maneuvering goes wrong, terribly wrong. Why is the turn to argue sometimes foregone, vital elements banned, and flows of junk communication put in its stead? Argumentation goes on autopilot, generating discourses as if they were reasonable products of agents, but basically the discourse is a veneer for reasons that matter to no one in particular. Put, differently, when are the costs of making an argument outweighed by the incentives to remain altogether silent, to substitute wholly specious reasoning for what should be tested critically, or to defer genuine argument while interests proceed in quest for advantage basically without sustained opposition? An argument community can fail when state-of-the-art standards for critical-rational appraisal of communication are systematically undermined, corrupted and suborned.

Consider three examples of the weakening of argumentation through the creation of moral hazard. Moral hazard is an anxiety of $19^{\text {th }}$ century insurance agencies that were expanding home-owner policies (Baker 1996). The provision of insurance was driven by the need to offset anxieties about future risk of harm. Insurance creates a moral hazard when it pays more for a policy-holder to burn down his house than it does to endure the costs of a fire. So, too, moral hazard occurs in argumentation when either: (a) it pays to voice partisan opposition, even though an argument is well supported or (b) it pays not to object to an argument, even though one understands it to be much weaker than claimed or entirely false. Justification turns to rationalization when proving a correct, informed assessment of a claim is less important than maintaining its impending, or established, truth or falsity. Individuals can be taken in by persuasive appeals; critical thinking preserves and extends reasoning autonomy. The question I wish to address is what kind of moral hazard can lead to the systematic undermining of rational autonomy in institutional settings of people trained, empowered, and credentialed to know better. What happening when argumentation itself goes "bad"?

5.1 Economics, Markets and Argument. Economic regulation requires the ratings of bonds. Investment offerings have proven risks. Past returns on investment is used as an indicator of future 
expectations. Bond ratings were trusted as reliable indicators of the amount of risk. Two shifts occurred that changed this. First, investment banks and savings banks merged, providing a lot of capital seeking new investments. Derivatives pooled housing loans from different parts of the country and sold them as bonds that would benefit from the low rate of default and the rising prices of housing, encouraged by low interest rates. Investment firms bought mortgages and pooled risks, inducing banks to lower standards of proof and to seek more loan applicants. The bond rating agencies treated the derivative pools as if they were similar to other pools of home loans, not taking into account the variable risk factors calculated into the mix of high and lower risk home loans. Bond ratings failed to test the accuracy of representation, while home loan lenders encouraged misrepresentation by reversing presumption. Proof of credit was linked to rising home prices rather than ability to pay, through subprime loans. Meanwhile, the Federal Reserve abetted this new standard by failing to file fraud cases while at the same time barring states from passing their own standards for checking loans. The payoff for not checking arguments tightly was great, the advantages of stopping the game was great as well. The argument thus shifted from checking standards of representation to permissive analogy, a thinking that moved an institution from strong evidence to weak. Many within the finance and lending industry recognized the shift was not sustainable, but to work they had to meet their quotas and make the sales. Thus, moral hazard effects markets, an operation otherwise reputed for conservative standards, cautious behavior, and accounting for risk before reward (Cassidy 2009; Lewis 2010).

5.2 Science argumentation. The question of anthropogenic climate change is coming ever closer. Storms, droughts, ice melting added public salience to a controversy that has extended over the last several decades. For most of the controversy, the question was confined largely to a small but global scientific community. The community had positive influence with international conferences in Japan, reaching a consensus about carbon emissions as a human induced cause of climate change. The causes were clear, who should bear what portions of the costs were not. Recently, the Canadian government has been reluctant to allow scientific reports bearing on the climate issue to be accessed. Acceding to public outcry, response occurs but is slowed by the "bureaucratic fallacy"-delay, redaction and exception. Key political office and departments are exempted from the obligations to provide studies, those actually provided are exten-

(C) G. Thomas Goodnight. Informal Logic, Vol. 33, No. 4 (2013), pp. 510530. 
sively redacted, and personnel are always in short supply (Amber 2013). In the United States, climate deniers took pride in questioning the science and some took to religious inspired counterargument. Politicians engage in rhetorical excess, but the question of climate comes down to who bears the risks. Anticipating the rise of sea levels, insurance rates were due to go up for the North Carolina shores. The legislature would not stand for this, so they banned evidence on "sea rise" from debate on coastal policy. Democratic North Carolina Governor Bev Perdue faced the question of signing this monument to ignorance, and demurred. The failure of moral courage technically may not be a fallacy but it certainly undermines the character of a forum. Legislatively banning or bureaucratically retarding the consideration of evidence all but encourages a fallacious climate of reasoning, and it certainly fortifies policy based upon ignorance.

5.3 Networked argument. The internet is a space that offers great access to ephemeral and enduring communities of argument. In the last decade, nonprofit firms have been transformed by greater public access. Science has slipped from its specialized boxes and appears in public discussions. Climate science sites invite argument where the norms of participating and debating scientific findings and implications for practice are discussed. The internet is also a space for moral hazards. The risks of engaging other minds have never been greater. Nonverbal cues are not present. Participation may or may not have or invite off line interaction. Platforms double-code communication, with little notice or control. Propaganda does not so much raise masses as spur mobs. The intent of an argument unwinds sentiment from audience, incidentally connected. Norms of exchange shared among one community are not shared by others; satire that confirms an open society becomes revised as a gesture of disrespect that offends another. Even as democratic participation widens, mass media seed popular opinion and imitate its loose commitment to evidence, precision, and judgment. Texts thin. Fragments multiply. Expectations hang. The tasks of informal logic have never been greater. Software that works on 'relevance' feeds us back our own opinion. The editor has died to make this all possible. Moral accomplishments are possible on the internet, but so too are the risks of moral hazard. New media confronts practical reasoning and the problem of other minds with new contexts. Communication platforms simulate human communication and sponsor argument exchange in ways that accumulate and blend discourse, image and design. Thus, argumentation teachers are challenged to adapt and transform studies in critical

(C) G. Thomas Goodnight. Informal Logic, Vol. 33, No. 4 (2013), pp. 510530. 
thinking to practices such as hypertext advocacy and network controversy.

\section{Twenty-first century studies}

The problem of other minds persists because common sense tells us that there is an asymmetry between access to knowledge of one's own state and access to information of the states of others. The diverse language games of a global society confirm this intuition anew in the multiple rules that invite ingenious engagement. Further, the question of other minds grows more pressing, as the indeterminacy of mind itself finds articulation: Michael Tooley (n.d.) asks: "Can one, or could one, for example, have justified beliefs (a) about other humans, both normal humans and humans at various stages of development, or decline? (b) About various non-human animals? (c) About possible extraterrestrials with a very different physiological makeup? (d) About super-computers?" Alterity can be posed as a question of differences brought about by condition, material, and scale. Yet, the otherness of an other mind may be discovered, too, merely in the mis-projection of reasonable expectations. Ideally such errors would invite cosmopolitan self-reflection on the assumed, grounded practices of argument, calling into appraisal common assumptions about rule standing, conditions of trust, and asymmetrical costs to expressing disagreement.

The problem is both conceptual and material, formed initially with the question: how can I appreciate an other's pain. The peculiar quality of pain is that coping with it changes the brain, so experiences of the self are not consistent; indeed, pain can remain even after the physiological cause weakens or no longer persists. The contemporary coordination of pain management involves an argumentative turn, the departure from the efficient exchange to an appreciation to talk with others who share similar interests. Subramaniam et al. (1999) found that most subject were relieved to shift discussion of pain from family members to experts and fellow sufferers who embraced a turn to the topic. The problem of other minds requires postconventional appreciation of the reciprocal construction of mind and brain, the conceptual and material resources engaged in the act of turning to argue. The problem of other minds also requires understanding the consequences of acts of access for groups perhaps disbursed spatially but bound by common condition and imagined connections. 
Such a cosmopolitan project requires continuous work with the virtues of argument and the problem of other minds. The efforts I have in mind are collaborative, an engagement in lateral thinking, that extrapolates through critical appraisal of long-standing controversies and interpolates the possibilities of somewhat novel sequences building into alternative futures. To sum, five lines of inquiry are connected in this paper.

6.1 Philosophical controversy. The essay takes up inquiry into a traditional debate and subsequent developments from modern philosophy. I think that our community has reached a point where we may wish to do critical studies on philosophical argumentation as a practice. The idea is to address the beginnings of issues that are subject to contemporary technical debate and to see if they may be better solved by taking them down alternative paths. The palaces of positivism, although lately in ruins, continue to dazzle with interesting argumentation. It is of interest to see how the arguments may be recast in other ways. Is this always a good idea? The rhetorician's view of the problem of other minds is well known. How can the gullible and weakwilled be persuaded? There are other, better ends, however strategic. Ingenuity is a virtue of argument that permits interlocutors to resolve an impasse, to raise or lower standards for coming to agreement, and to correct unshared mutual understanding, learning from mistakes. Philosophical controversy can be read for the ingenuity of philosophers addressing issues that otherwise get repeated and take on cumbersome visage.

6.2 Rhetorical cognition. To play language games imparts indirect knowledge of other minds. So efficient is communication that sometimes this otherness becomes forgotten. Otherness is confirmed, however, when arguments are not easily discounted, resolved or set aside. Ingenuity must intervene. A reflexive turn occurs when routine is broken and reciprocal flow of expectations ruptured. The negative can be articulated as contention, objection, contestation, antagonism, mimicry and mocking; the routes of engaging an other mind may appear to be direct but reciprocal thinking is always carried along by language games playing within, through or out of a trope. Shifts in tropes that discipline a dispute may be helpful in creating new possibilities of understanding or agreement. The climate debate is in trouble because utilitarian logic deployed by evidentiary representations is too fearsome to even acknowledge basic evidence. Paradox offers better framing (Sorensen 2003). Climate is the problem of the heap. When does humanity switch from just another day of

(C) G. Thomas Goodnight. Informal Logic, Vol. 33, No. 4 (2013), pp. 510530. 
more carbon into setting in motion irreversible long-term disaster? The paradox of how short and long term interests intersect with productive resistance could underwrite a different way of thinking about involvement in the issue.

6.3 The turn to argue, for others. Understanding the turn to argument can be figured as sometimes a dimple at other times a failure to anticipate properly or completely the thinking of others. Shared validity conditions set limits on the scope of a debate; speech acts presuppose shared rules of articulation and evaluation - in order to make sense. The rules projected for any given situation may be unshared, however. The trust necessary to create a bridge in which differences are discussed may not be available. Daniella Adams (2004) critiques speech act theory from the standpoint of group access. Since the U.S. Supreme Court's Brown versus Board of Education ruling, the trust necessary to converse across lines of racial divide simply does not exist for many in the United States. The risks to coming to a consensus that is incorrect may be endurable for one, but not for others; open argument may be possible within a group, but not across groups with historically different social status. Seyla Benhabib (2006) speaks to the project of criticalcosmopolitanism where controversies erupt between advocates with different cultural perspectives, but the result is a learning moment or democratic iteration-such as the hijab debate in France. The turn to argue, to sustain, to expand or contract, or break off, perhaps then renew - all these entry and exit points mark argument as a reflexive turn focusing urgent inquiry on the taken for granted everyday arrangements of communication. Open discussion may create or renew appreciation for reasonable differences.

6.4 Communities of practice. Argument communities appear to flourish following structure-function models analogous to Aristotle's polis. Judgment is cultivated at the juncture of ethical, political and rhetorical practice. The process flourishes when argument moderates between extremes. Vico sees the practice of argument as pulled by gestures toward the dignity of the audience in its uncertain position when deciding the gravity of its own risks in relation to the outcome of a case. The social positions of arguers do not distribute risks equally, however; and procedural guarantees work within and against actual performance of argument. So, the standards of a field, the practices of trusted institutions, the standards by which argumentation is deployed to fulfill professional duties and public expectations can

(C) G. Thomas Goodnight. Informal Logic, Vol. 33, No. 4 (2013), pp. 510530. 
change. Moral hazard is a problem where repositioning of standards and proof in key exchanges may make a field flourish for a while, only to contribute to its crash in the long run. Such changes may aid an institution in avoiding tough evidence that its own practices and standards of judgment are questionable, but only for a time. Virtue ethics is necessary to remind us that just as our own character is shaped by the cognitive structures of communicative reason, so too the reasoning practices of institutions themselves are at risk in change in argument practices. Sometimes change is good even necessary, for it is not the case that Aristotle's equilibrium benefits everyone equally or distributes risks of error fairly.

6.5 Networking argumentation. Moral hazard is not merely a problem attached to personal or professional life. Moral hazard is also attached to media that disguise risk by circulating controversies by leaps in pace, scope, and scale. Informal logic and critical thinking are projects that address well the habits of a mass media age saturated with militaristic propaganda and consumer advertising. The mass media is still with us, of course. The question remains open: what are the possibilities for great achievement and the mutation of fallacious reasoning and poor thinking given network of exchange afforded by new, participatory media platforms? Mapping global controversies at MIT finds the internet and sentiment to be most analogous to weather formations, unpredictable and shifting, sunny and mild or cloudy and stormy.

Vico believed that rhetoric changes with time; the problems of one era are not those of another. Critical argumentation studies describe, reflect upon, and intervene into trajectories of argument of the past in order to extrapolate understanding into emergent contemporary and to interpolate alternative possibilities into future development. In Homer's time, Odysseus wakes up on a foreign beach and asks a stranger: Am I talking to human or god? In the twenty first century, we pop up our screen and wonder: Am I arguing with a human agent or hooked up globally to a machine?

\section{References}

Allen, D. S. (2004). Talking to Strangers: Anxieties of Citizenship since Brown versus Board of Education. Chicago, IL: University of Chicago Press. 
Avramides, A. (2001). Thomas Reid and knowledge of other intelligent beings. Other Minds. New York, NY: Rutledge, 139-180.

Ayer, A.J. (1946). Other minds. Aristotlean Society Supplement, 20, 188-197.

Amber, A. (2013, May 20). What the government is hiding should make Canadians blush in horror. Huffington Post.

Baker, T. (1996). On the genealogy of moral hazard. Texas Law Review. 75: 2, 237-292.

Benhabib, S. (2008). Another Cosmopolitanism. Berkeley, CA: Berkeley University Press.

Cassidy, J. (2009). How Markets Fail: The Logic of Economic Calamities. New York: Farrar, Straus and Giroux.

Eemeren, F.H. van. (2010). Strategic Maneuvering in Argumentative Discourse: Extending the Pragma-dialectical Theory of Argumentation. Amsterdam: John Benjamins.

Eemeren, F.H. van and Houtlosser, P. (2003). The development of the pragma-dialectical approach to argumentation. Argumentation, 17, 384-403.

Everett, T. J. (2000). Other voices, other minds. Australasian Journal of Philosophy, 78:2, 213-222.

Feigel, H. (1958). Other minds and the egocentric predicament. The Journal of Philosophy, 55: 23, 978-987.

Franks, D. D. (1997). Neurosociology: The Nexis Between Neuroscience and Sociology. New York, NY: Springer.

Goodnight, G.T. (2003). Predicaments of communication, argument, and power: Towards a critical theory of controversy. Informal Logic, 23, 119-138.

Goodnight, G.T. (1991). Controversy. In D. Parson (Ed.), Argument in Controversy: Proceedings of the Seventh SCA/AFA Summer Conference on Argumentation (pp. 1-13). Annnandale, VA: Speech Communication Association.

Habermas, J. (1983). Theory of Communicative Action. Volume I. Reason and Rationalization of Society. Thomas McCarthy (Trans.). Boston, MA: Beacon Press.

Hampshire, S. (1969). Vico and the contemporary philosophy of language. In G. Tagliacozzo and H.V. White (Eds.). Giambattista Vico: An International Symposium (pp. 475-495). Baltimore, MD: Johns Hopkins University Press.

Harish, A. (2012). New Law in North Carolina Bans Latest Scientific Predictions of Sea Rise.

http://abcnews.go.com/US/north-carolina-bans-latest-sciencerising-sea-level/story?id=16913782\#.UZGFObWsh8E 
Hyslop, A. (2010). Other minds. The Stanford Encyclopedia of Philosophy (Fall 2010 ed.), Edward N. Zalta (ed.), URL = $<$ http://plato.stanford.edu/archives/fall2010/entries/otherminds/>.

Hyslop and Jackson. (1972). The Analogical Inference to Other Minds'. American Philosophical Quarterly, 9, 168-176.

Lewis, M. (2010). (2010). The Big Short: Inside the Doomsday Machine. New York, NY: Norton and Company.

Lock, D. (2012). Just What is Wrong with the Argument from Analogy? Australasian Journal of Philosophy, 51:2, 153-156.

Malcolm, N. (1958). "I. Knowledge of Other Minds," The Journal of Philosophy, 55:23, 969-978.

Mill, J. S. (1872). An Examination of Sir William Hamilton's Philosophy. London, Longmans.

Noordhof, P. (2011). Current Issues in the Philosophy of Mind. In J. Garvey (Ed.), The Continuum Companion to Philosophy of Mind (pp. 239-279). Continuum: New York, NY: Continuum.

Olshewsky, T. M. (1974). VII. The Analogical Argument for Knowledge of Other Minds Reconsidered. American Philosophical Quarterly, 11:1, 63-69.

http://plato.stanford.edu/entries/other-minds/

Russell, B. (1970). Analogy. In Thomas O. Buford (Ed.). Essays on Other Minds (pp. 3-8). Urbana, IL: University of Illinois Press.

Sayward, C. (2003). A Defense of Mill on Other Minds. Dialectica, 57:3, 315-322.

Sorensen, R. (2003). Paradox: Philosophy and the Labyrinths of the Mind. Oxford: Oxford University Press.

Stemmer, N. (1987). The Hypothesis of Other Minds: Is it the Best Explanation? Philosophical Studies: An International Journal for Philosophy in the Analytic Tradition, 51: 1, 109121.

Subranmaniam, V., Stewart, W. \& Smith, F. (1999). The Development and Impact of a Chronic Pain Support Group: A Qualitative and Quantitative Study. Journal of Pain and Symptom Management, 17:5, 376-383.

Thornton, S. P. (nd) Solipsism and the Problem of Other Minds. Internet Encyclopedia of Philosophy. http://www.iep.utm.edu/solipsis/

Tooley, M. (nd) Epistemology Notes. Chapter 6. Other Minds. http://spot.colorado.edu/ tooley/LectureNotes.html

Vico, G. (1996). G. A. Pinton and A W. Shippee, Trans., Eds., The Art of Rhetoric (Institutiones Oratoriae, 1711-1741). Amsterdam, The Netherlands: Rodopi. 